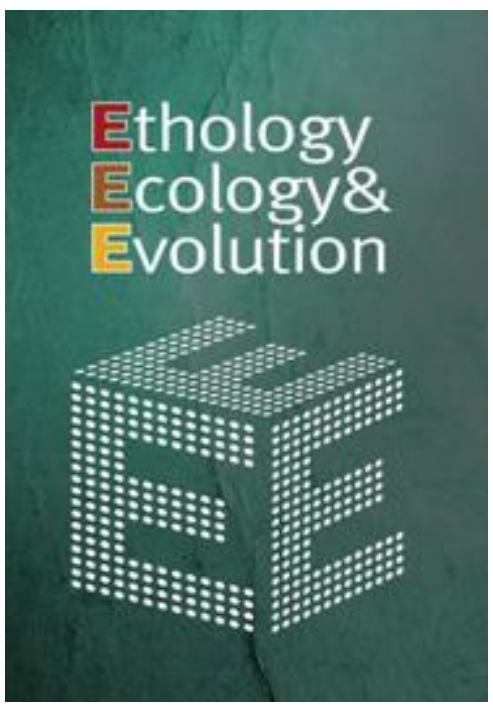

\title{
Adaptations to prey base in the hypercarnivorous leopard cat Prionailurus bengalensis
}

\begin{tabular}{|r|l|}
\hline Journal: & Ethology Ecology \& Evolution \\
\hline Manuscript ID & TEEE-2019-0073.R1 \\
\hline Manuscript Type: & Original Article \\
\hline Author: & n/a \\
\hline Complete List of Authors: & $\begin{array}{l}\text { Hisano, Masumi; Lakehead University, Faculty of Natural Resources } \\
\text { Management } \\
\text { Newman, Christopher; University of Oxford, Wildlife Conservation } \\
\text { Research Unit, Department of Zoology }\end{array}$ \\
\hline Keywords: & $\begin{array}{l}\text { Adaptive foraging, Feeding ecology, Felidae, Hypercarnivory, Iriomote } \\
\text { cat }\end{array}$ \\
\hline &
\end{tabular}

\section{SCHOLARONE \\ Manuscripts}


$1 \quad$ Original Article

2 Adaptations to prey base in the hypercarnivorous leopard cat Prionailurus bengalensis 3

4 Masumi Hisano ${ }^{1, *}$ and Chris Newman ${ }^{2}$

5

$6 \quad{ }^{1}$ Faculty of Natural Resources Management, Lakehead University, 955 Oliver Road, Thunder

7 Bay, ON P7B 5E1, Canada

8

$9{ }^{2}$ Wildlife Conservation Research Unit, Department of Zoology, University of Oxford,

10 The Recanati-Kaplan Centre, Tubney House, Abingdon Road, Tubney, Oxon OX13 5QL, UK

11

$12{ }^{*}$ Corresponding author. Email address: mhisano@lakeheadu.ca (M. Hisano).

13 ORCID: 0000-0002-3869-8542

14 


\section{ABSTRACT}

16 Investigating biogeographical variations in diet composition can help understand the adaptability

17 and generalism of species. Although the dietary adaptability of omnivorous mesocarnivores is

18 well established, far less work has explored how more specialist hypercarnivores optimise their

19 diets. By reviewing 11 studies of the leopard cat (Prionailurus bengalensis), we quantitatively

20 examined how dietary composition varies over the wide range of biomes they occupy in Asia.

21 Specifically, we contrasted the diet of the Iriomote Island sub-species (south-western Japan),

22 where native rodents are absent, with that of the mainland. Leopard cat diet typically comprised

23 mammals, birds, amphibians, reptiles, and invertebrates. In Iriomote Island, however, the low

24 relative frequency of occurrence of small mammals (only introduced rats) was compensated by

25 higher frequencies of reptiles and amphibians compared to the mainland. Consequently, trophic

26 diversity and dietary niche breadth were higher for leopard cats in Iriomote Island than for the

27 mainland. This shows that even hypercarnivorous species can use trophic plasticity to adapt to

28 local prey availability. Given that rodent numbers often fluctuate substantially over time, the

29 availability of alternative prey, such as herptiles, may be vital for the conservation of the leopard

30 cat, and especially the critically endangered Iriomote cat. More generally, the trophic versatility

31 of hypercarnivores must be considered when assessing their vulnerability to environmental

32 change.

34 Keywords: Adaptive foraging; Feeding ecology; Felidae; Hypercarnivory; Iriomote cat 35 36 


\section{Introduction}

38 The temporal and spatial distribution of trophic resources can influence life-history (Macdonald

39 and Johnson 2015). Feeding behaviour is, therefore, important for understanding animal ecology

40 (Pineda-Munoz \& Alroy 2014). Animals may be primarily herbivorous, omnivorous or

41 carnivorous, but vary in the extent to which they are specialists or generalists within these

42 categories according to their trophic range and the diversity of food types they consume (Virgós

43 et al. 1999; Pineda-Munoz \& Alroy 2014). Specialists usually exhibit greater vulnerability to

44 environmental perturbation, while generalists are more versatile and resilient (Clavel et al. 2011).

45 Dietary adaptability has been well established among members of the Carnivora that

46 have a mesocarnivorous / omnivorous diet (i.e., consuming 50-70\% vertebrate prey, with the

47 balance made up of non-vertebrate foods; Van Valkenburgh 2007) (e.g., Virgós et al. 1999; Zhou

48 et al. 2011; Díaz-Ruiz et al. 2013), yet far less work has examined how more specialist

49 hypercarnivores (consuming $>70 \%$ vertebrate flesh; Van Valkenburgh 2007) may optimise their

50 diets in relation to regional prey availability. Clearly, such adaptability is crucial for obligate

51 carnivores to transcend biomes, resulting in extensive biogeographical distributions. In contrast,

52 predators specialising on a limited, or fixed, variety of key prey species will always be restricted

53 by the distribution of their prey base. In conservation terms, the (in-)flexibility of a carnivore's

54 diet determines their specific vulnerability to prey depletion (Wolf \& Ripple 2016), where more

55 versatile carnivores will be more resilient. The implications of a restricted diet for the

56 conservation of many hypercarnivorous Carnivora, must therefore not be overlooked (Kitchener

57 et al. 2017), because many are 'At Risk', notably felids (of 41 felid species from 14 genera,: four

58 species are Endangered (10\% of all felid species),: 12 species are Vulnerable (29\%), and nine 
59 species are Near Threatened: (22\%); https://www.iucnredlist.org). Among these, small felids are

60 particularly understudied (Macdonald et al. 2015) due to their lower detectability and

61 approachability (Anile \& Devillard 2016).

62 Systematic investigations of geographical variations in small felid (Felis spp.) diet have

63 identified dietary switching. For instance, consumption of rodents by wildcats ( $F$. sylvestris) in

64 Europe was significantly reduced in locations where rabbits (Oryctolagus cuniculus) were

65 present (Lozano et al. 2006; Apostolico et al. 2015); similarly, the consumption of rabbits by

66 feral cats (F. catus) in Australia decreased when consumption of rodents and small dasyurids

67 increased (Doherty et al. 2015). In comparison, assessments of the diets of small felids in Asia

68 are lacking and require further research (Kitchener et al. 2017). Particularly challenging is that

69 small hypercarnivorous felids are especially sensitive to changes in their natural environments,

70 and tend not to be able to exploit the novel niches provided by urbanisation as effectively as

71 many other mesocarnivores (Lewis et al. 2015).

72 To address this knowledge gap, we focus here on the leopard cat [Prionailurus

73 bengalensis; head-body length 500 to $640 \mathrm{~mm}$; weight 2,000 to 3,500 $\mathrm{g}$ (based on adults in

74 Thailand; Grassman et al. 2005)], for which sufficient reports exist to support a systematic

75 review (a quantitative assessment) of its dietary flexibility. Leopard cats are common throughout

76 their range and categorised as 'Least Concern' in the IUCN Red List of Threatened Species

77 (Ross et al. 2015), although they are locally threatened by poaching and the exotic pet trade (Lau

78 et al. 2010). Leopard cat population status is, however, strongly dependent on habitat quality,

79 and land-use changes threaten leopard cat populations in many areas [e.g., south-western India,

80 Tsuhima Island (western Japan); Ross et al. 2015]. The leopard cat's diet is comprised mainly by 
81 rodents across its range, supplemented by other vertebrates and invertebrates (Watanabe 2009).

The Critically Endangered (IUCN) Iriomote Island subspecies ( $P$. b. iriomotensis) in

83 south-western Japan (hereafter Iriomote cat) provides a particularly informative contrast because

84 native rodents are absent from this island (Izawa 2005; Watanabe 2009), although introduced

85 black rats (Rattus rattus) are present in low abundance; no house mice (Mus musculus) have

86 been introduced (Okinawa Prefecture 2018). Furthermore, there are no intra-guild mammalian

87 predators on Iriomote, except for feral cats, although these are currently restricted to urban areas

88 where they feed predominantly on garbage (Watanabe et al. 2003); given that the presence of

89 sympatric carnivores can influence dietary niche breadth and composition of small cats through

90 competition, modifying their distribution and activity patterns (Drouilly et al. 2018). This unique

91 prey situation in Iriomote provides a particularly stringent test of how leopard cats may adapt

92 their diets according to prey diversity ( $c f$. Lozano et al. 2006; Dohety et al. 2015), with

93 implications for their population dynamics (e.g., Pavey et al. 2008).

94 We base our systematic review on the most contemporary literature, including peer-

95 reviewed articles and regional status reports, which we use to i) quantitatively assess the trophic

96 breadth and adaptability of leopard cats: and ii) how the specific depauperate prey-base in

97 Iriomote might be accommodated by switching to alternative prey types (e.g., Nakanishi \&

98 Izawa 2016). We predict that trophic range of Iriomote cats will be broader than mainland

99 populations due to the absence of native rodents on Iriomote. We then use inferences drawn from

100 this systematic review to evaluate how the trophic plasticity and adaptive potential of small

101 hypercanivorous cats may affect their success generally.

102 


\section{Materials and methods}

\section{Literature and data compilation}

105 We searched for studies quantifying leopard cat diet composition written in English, Japanese, 106 and Chinese up until March 2018, using Google Scholar (https://scholar.google.com) and ISI

107 Web of Science (http://apps.webofknowledge.com). We used various combinations of keywords:

108 in English, "leopard cat", "Prionailurus bengalensis", "Felis bengalensis" (a synonym), "diet",

109 "food"; in Japanese, "Iriomote-yamaneko" (the subspecies in Iriomote), "Tsuhima-yamaneko"

110 (the subspecies in Tsushima Island; P. b. euptilurus), and "shokusei" (diet); and in Chinese, 111 "bàomāo" (leopard cat), "shíxìng” (diet), and "shíwù" (food).

112 We compiled leopard cat diet data from reviewed literature that met the following

113 criteria. Studies must have: (i) examined $>20$ scats or stomach contents (Doherty et al. 2015)

114 with sufficient detail to re-calculate the number of items belonging to each food category that

115 occurred, and relative frequency of occurrence $[\mathrm{RFO}(\%)=$ the number of occurrences of each

116 food category / the total number of food categories occurring $\times 100]$ of different food categories

117 against the total number of all food items (Zhou et al. 2011; Hisano et al. 2019); (ii) presented all

118 recognisable prey taxa present in faeces / stomachs (i.e., those reports focusing only on the

119 presence of a single taxa, such as frogs, without describing other prey categories, were

120 excluded); and (iii) covered at least one entire year (Zhou et al. 2011; Doherty et al. 2015), to

121 ensure that both dry and rainy (or, fire and non-fire) seasons in tropical/sub-tropical areas, or all

122 four seasons in temperate/sub-alpine areas (Hisano et al. 2019) were included.

123 To compile dietary data, we divided prey types consumed into seven main categories

124 based on Doherty et al. (2015): 'small mammals' (<500 g: rodents, insectivores, pikas; Rattus 
125 norvegicus was the largest rodent recorded in the studies reviewed), 'other mammals' (i.e.,

126 medium and larger mammals $>500 \mathrm{~g}$ including rabbits/hares, flying foxes, and ungulates), 'birds',

127 'reptiles', 'amphibians', 'fishes', and 'invertebrates'. We then extracted, or re-calculated, RFO

128 according to the food item categories represented in each study used (following Zhou et al. 2011;

129 Hisano et al. 2019). We also calculated Shannon's diversity index $\left(H^{\prime}=\sum_{i=1}^{S} P_{i} \ln P_{i}\right)$ and Levins'

130 niche breadth index $\left(B={ }^{1} / \sum_{i=1}^{S} P^{2}\right.$ ) based on RFO values to quantify trophic diversity.

\section{Statistical analysis}

133 After standardising for sampling method inconsistencies (see Supplementary Information), we

134 conducted Friedman's test to examine whether diet composition (RFO) differed overall between

135 all the study sites. In a second step we then also compared diet between mainland sites only,

136 excluding Iriomote. We applied Mann-Witney $U$ tests to examine whether Shannon's and Levins'

137 indices varied between the mainland and the population living on Iriomote. We also performed a

138 permutational multivariate analysis of variance (PERMANOVA; see Hisano et al. 2016, 2019) to

139 assess the extent to which diet composition (RFO) differed between 'Iriomote Island' versus

140 'mainland (i.e., all other study areas)'. If overall dissimilarity in dietary composition was found

141 between the geographical categories, Chi-squared tests were applied to compare RFO of each

142 food category following the methodology of previous studies (Hisano et al. 2019). Finally, we

143 performed a principal component analysis (PCA), based on RFO, to visualise the spatial

144 ordination of the seven food categories (see above) and geographical locations.

145 We also performed additional tests, described in Supplementary Information, to examine whether

146 the source of dietary data (stomach contents vs faeces), or the role of carrion in some study sites 
147 had any bearing on our conclusions.

148

149 Results

150 A total of 24 studies was reviewed (Table S1) for which data quality in 11 was sufficient to

151 support analysis (Table 1; Fig. 1). Overall, leopard cats ate a similar diet composition across

152 mainland regions (Friedman test: $P=0.863$ ); however, including Iriomote study data

153 substantially increased diet dissimilarity (Friedman test: $P=0.124$ ) (Table 1). Specifically

154 contrasting Iriomote cat to the mainland leopard cat studies clarified this significant dissimilarity

155 (PERMANOVA: $F=15.70, R^{2}=0.64, P=0.011$ ). This arose from differences in the RFO of

156 specific food categories between Iriomote and the mainland. The RFO of reptiles [e.g., lizards,

157 skinks; $\chi^{2}=9.73, P=0.002$ ) and amphibians (frogs; $\chi^{2}=10.17, P=0.001$ ); Fig. 2], was

158 significantly greater in Iriomote (with the result for birds being marginally below significance

159 (Chi-squared test: $\left.\chi^{2}=2.63, P=0.105\right)$, compensating for the significantly lower reliance on

160 small mammals (Chi-squared test: $\chi^{2}=59.6, P<0.001$ ), due to the absence of native rodents.

161 Our results were robust as alternative approaches (G-test, Mann-Whitney's $U$ test) also produced

162 the same results (see Supplementary Information). This resulted in the Iriomote cat exhibiting

163 greater trophic diversity (Mann-Whitney $U$ test: $P=0.006)$ and niche breadth $(P=0.006)$ indices

164 than the mainland dataset (Table 1).

165 The first two axes of PCA based on RFO explained $78.57 \%$ (PC1: $53.37 \%$, PC2:

$16625.20 \%$ ) of the overall variation in leopard cat food composition across studies (Fig. 3; Table

167 S2). The first PCA factor, $\mathrm{PC} 1$ represented a greater frequency of amphibians $(\mathrm{PC} 1=0.48)$ and

168 birds (0.44) in the diet, with a lower frequency of small mammals (-0.50). In Iriomote, the 
169 positive loading on $\mathrm{PC} 1$ corroborated that cats ate a higher RFO of amphibians and birds; in 170 contrast, the negative PC1 loading showed that in the Philippines, India, Korea, and Borneo 171 consumed a higher RFO of small mammals (Fig. 3). PC2 loadings indicated a greater frequency 172 of other mammals $(\mathrm{PC} 2=0.60)$ and fishes $(0.38)$, and a lower frequency of invertebrates $(-0.55)$ 173 and reptiles (-0.39). Leopard cats in India and Iriomote "Ir4" consumed 'other mammals' and 174 fishes with higher frequency (positive PC2); while those in Iriomote "Ir1" and Singapore ate 175 reptiles and invertebrates with higher frequency (negative PC2; Fig. 3; Table S2).

176 We detected no substantial effect of data source (stomachs vs faces) or the role of 177 carrion influencing our findings (see Supplementary Information).

179 Discussion

180 This is the first study to quantitatively examine the adaptability of leopard cat diet. We found 181 that, despite being an obligate hypercarnivore, the leopard cat still exhibited wide trophic 182 diversity, particularly through its capability to adapt to the different food types available on 183 Iriomote Island. This resulted in a Shannon index of 1.07 (range, 0.69-1.66) and a Levins index 184 of 2.49 (range, 1.49-4.74; Table 1). These indices are very comparable to those for the much 185 more generalist and omnivorous Carnivora genus Martes range, respectively 1.38-2.08 and $1862.07-3.69$, (Zhou et al. 2011). This trophic plasticity, and the leopard cats' capacity to modify 187 the RFO of key food categories comprising its diet, likely contributes to its occupation of a wide 188 geographic range throughout Asia (Ross et al. 2015) over a diverse range of habitats (Mohamed 189 et al. 2016).

190 As a particular case in point, we found that in the special instance of Iriomote Island, in 
191 the absence of native rodents, leopard (Iriomote) cats compensated by making greater use of

192 herptiles (Nakanishi \& Izawa 2016) and marginally birds, especially flightless rails (Rallidae). In

193 addition, they also scavenged wild boar (Sus scrofa), and utilised novel food sources, such as

194 Ryukyu flying foxes (Pteropus dasymallus; a species of Chiropteran endemic to the Ryukyu

195 Islands, south-western Japan). These medium-/large- carrion species were reported by both the

196 "Ir4" (Nakanishi \& Izawa 2016) and "Ir1-3" (Sakaguchi and Ono 1994; Watanabe et al. 2003;

197 Watanabe 2012) studies. Consequently, these studies produced Shannon's and Levin's indices of

$198 \quad 1.66$ and 4.74 , much broader than the 0.99 and 2.17 typifying mainland sites. This shows that

199 although leopard cats tend not to predate on herptiles or birds substantially under normal

200 circumstances of prey availability (RFO $<10 \%$; Fig. 2), they exhibit dietary switching (as seen in

201 omnivorous carnivores - Zhou et al. 2011; Coogan et al. 2018; Hisano et al. 2019) to utilise

202 unusual prey to a greater extent in the absence of their favoured food categories. On Iriomote,

203 they exploited amphibians, reptiles, and birds at respectively $21.2 \%, 21.9 \%$, and $23.0 \%$ (RFO) of

204 their total diet, versus just $2.4 \%, 4.5 \%$, and $12.3 \%$ elsewhere. Indeed, even within Iriomote, the

205 marked spread of the four studies on Axis PC2 of the ordination (Fig. 3), suggests that, even on a

206 small island, there may still be substantial flexibility in diet. We were able to discount that this

207 'within-Iriomote' variation could have arisen simply from sampling methodology inconsistency

208 across our study sample set (i.e., Nakanishi \& Izawa (2016) analysed stomach contents vs the

209 other 10 studies that examined faeces, where faecal analysis may underestimate certain prey

210 items due to differences in the proportion of indigestible parts (Klare et al. 2011)) by excluding

211 Nakanishi’s \& Izawa's (2016) study, which still gave similar results (see Supplementary

212 Information). 
Across study sites, leopard cats also adapted their diets to best utilise suitable local prey

214 availability within community compositions. For example, in India the leopard cat consumes a

215 variety of ungulate carrion ( $16.7 \%$ RFO vs $0-5 \%$ elsewhere), including gorals (Naemorhedus

216 goral), cattle (Boss spp.), and dzos (B. grunniens $\times$ B. primigenius) (Bashir et al. 2014). This

217 demonstrates that they can meet their dietary needs, even with much less reliance on actively

218 hunting. Moreover, in India their diet included the novel consumption of locally abundant pikas

219 (Ochotona spp.; RFO >20\%) in addition to other rodents (Bashir et al. 2014). Consuming these

220 atypical food sources enables leopard cats to adapt to habitats above $3000 \mathrm{~m}$ (asl) in the

221 Himalayas (Table 1). The substantial consumption of carrion in India versus hunting living prey

222 did not influence our conclusion, however, as evidenced by excluding scavenged items

223 (ungulates) from the PERMANOVA, which yielded consistently similar results (see

\section{Supplementary Information).}

225 Intra-guild prey competition can also constrain the prey types consumed by carnivores

226 (Tatara \& Doi 1994; May et al. 2008). Across most of its range, the leopard cat competes within

227 diverse carnivore communities (e.g., Cheyne \& Macdonald 2011), where we confirmed from the

228 literature that all mainland study areas included at least two other wild sympatric carnivore

229 species (potential competitors). On Iriomote Island the feral cat was the only other mammalian

230 predator present (Motokawa 2000; Watanabe et al. 2003); however these feral cats typically

231 inhabit human residential areas and rely heavily on refuse [ $>85 \%$ absolute frequency of

232 occurrence (FO: the number of each food item occurred / the total number of faeces examined $x$

233 100)] with animal prey $\mathrm{FO}<10 \%$. This lack of natural competitors in their natural habitat

234 potentially enables Iriomote cats to solely occupy the top mammalian predator trophic niche on 
235 the island. However, feral cat populations are expanding in Iriomote, risking dietary niche

236 overlap and competition for resources with Iriomote cats. Future studies should examine in more

237 detail how interactions with sympatric carnivores can affect leopard cat diet.

238 Given the trophic adaptability of leopard cats, we infer that they will not be especially

239 vulnerable to changes in prey base arising from changing seasonality (Pucek et al. 1993), or

240 climate change (Kausrud et al. 2008). They may, however, be vulnerable to intensified land-use

241 (Blaum et al. 2007) if this substantially reduces gross prey abundance across multiple categories

242 per population (e.g., Mohamed et al. 2016). In such human-altered environments, the

243 conservation of herptiles (e.g., Renken et al. 2004) may benefit leopard cats, while the protection

244 of forested habitat is important for conserving their denning sites (Mohamed et al. 2016).

245 Our broad conclusion is that non-specialised hypercarnivores, especially felids, may

246 utilise prey switching to succeed across various prey communities in different regions, mirroring

247 the trophic adaptability of omnivorous generalists (Zhou et al. 2011; Hisano et al. 2019).

249 Acknowledgements

250 We are grateful to Xingwen Loy for his courtesy to provide the graphic art of the leopard cat. We

251 also thank Dr. Shota Deguchi for his insights into the manuscript.

252 Funding: This research did not receive any specific grant from funding agencies in the public, 253 commercial, or not-for-profit sectors.

254 Conflict of Interest: The authors declare that there is no conflict of interest. 255 


\section{References}

257 Anile S, Devillard S. 2018. Camera-trapping provides insights into adult sex ratio variability in 258 felids. Mamm Rev. 48:168-179.

259 Apostolico F, Vercillo F, La Porta G, Ragni B. 2015. Long-term changes in diet and trophic 260 niche of the European wildcat (Felis silvestris silvestris) in Italy. Mamm Res. 61:109-119. 261 Bashir T, Bhattacharya T, Poudyal K, Sathyakumar, S, Qureshi Q. 2014. Integrating aspects of 262 ecology and predictive modelling: implications for the conservation of the leopard cat 263 (Prionailurus bengalensis) in the Eastern Himalaya. Acta Theriol. 59:35-47.

264 Blaum N, Rossmanith E, Jeltsch F. 2007. Land use affects rodent communities in Kalahari 265 savannah rangelands. Afr J Ecol. 45:189-195.

266 Cheyne SM, Macdonald DW. 2011. Wild felid diversity and activity patterns in Sabangau peat267 swamp forest, Indonesian Borneo. Oryx. 45:119-124.

268 Clavel J, Julliard R, Devictor V. 2011. Worldwide decline of specialist species: toward a global 269 functional homogenization? Front Ecol Env. 9:222-228.

270 Coogan SC, Raubenheimer D, Stenhouse GB, Coops NC, Nielsen SE. 2018. Functional 271 macronutritional generalism in a large omnivore, the brown bear. Ecol Evol 8:2365-2376.

272 Díaz-Ruiz F, Delibes-Mateos M, García-Moreno JL, López-Martín JM, Ferreira C, Ferreras P. 273 2013. Biogeographical patterns in the diet of an opportunistic predator: the red fox Vulpes 274 vulpes in the Iberian Peninsula. Mamm Rev. 43:59-70.

275 Doherty TS, Davis RA, Etten EJ, Algar D, Collier N, Dickman CR, Edwards G, Masters P, 276 Palme R, Robinson S. 2015. A continental-scale analysis of feral cat diet in Australia. J. 277 Biogeogr. 42:964-975. 
278 Drouilly M, Nattrass N, O'riain MJ. 2018. Dietary niche relationships among predators on 279 farmland and a protected area. J Wildl Man. 82:507-518.

280 Grassman LI, Tewes ME, Silvy NJ, Kreetiyutanont K. 2005. Spatial organization and diet of the 281 leopard cat (Prionailurus bengalensis) in north-central Thailand J Zool. 266:45-54.

282 Hisano M, Raichev EG, Peeva S, Tsunoda H, Newman C, Masuda R, Georgiev D, Kaneko Y. 283 2016. Comparing the summer diet of stone martens (Martes foina) in urban and natural 284 habitats in Central Bulgaria. Ethol Ecol Evol. 28:295-311.

285 Hisano M, Newman C, Deguchi S, Kaneko Y. 2019. Thermal forest zone explains regional 286 variations in the diet composition of the Japanese marten (Martes melampus). Mamm Biol. $287 \quad 95: 173-180$.

288 Izawa M. 2005. The ecological system of Iriomote Island from the perspective of the wild cat. 289 Biohistory 47. https://www.brh.co.jp/seimeishi/journal/047/research 21.html [accessed 5 290 December 2018] (in Japanese).

291 Kausrud KL, Mysterud A, Steen H, Vik JO, Østbye E, Cazelles B, Framstad E, Eikeset AM, 292 Mysterud I, Solhoy T, Stenseth NC. 2008. Linking climate change to lemming cycles. $293 \quad$ Nature. 456:93-97.

294 Kitchener AC, Breitenmoser-Würsten C, Eizirik E, Gentry A, Werdelin L, Wilting A, 295 Yamaguchi N, Johnson WE 2017. A revised taxonomy of the Felidae: The final report of 296 the Cat Classification Task Force of the IUCN Cat Specialist Group. Cat News Special $297 \quad$ Issue 11. 1:80.

298 Klare U, Kamler JF, Macdonald DW 2011. A comparison and critique of different scat-analysis 299 methods for determining carnivore diet. Mamm Rev 41:294-312. 
300 Lau MWN, Fellowes JR, Chan BPL. 2010. Carnivores (Mammalia: Carnivora) in South China: a 301 status review with notes on the commercial trade. Mamm Rev. 40:247-292.

302 Lewis JS, Logan KA, Alldredge MW, Bailey LL, Vande-Woude S, Crooks KR. 2015. The 303 effects of urbanization on population density, occupancy, and detection probability of wild $304 \quad$ felids. Ecol Appl. 25:1880-1895.

305 Lozano J, Moleón M, Virgós E. 2006. Biogeographical patterns in the diet of the wildcat, Felis 306 silvestris Schreber, in Eurasia: factors affecting the trophic diversity. J Biogeogr. 33:1076$307 \quad 1085$.

308 Macdonald DW, Johnson DDP. 2015. Patchwork planet: the resource dispersion hypothesis, 309 society, and the ecology of life. J Zool. 295:75-107.

310 May R, Van Dijk J, Wabakken P, Swenson JE, Linnell JD, Zimmermann B, Landa A. 2008.

311 Habitat differentiation within the large-carnivore community of Norway's multiple-use 312 landscapes. J Appl Ecol. 45:1382-1391.

313 Motokawa M. 2000. Biogeography of living mammals in the Ryukyu Islands. Tropics. 10:63-71. 314 Nakanishi, N., Ichinose, F., Higa, G., Izawa, M. 2009. Age determination of the Iriomote cat by 315 using cementum annuli. J. Zool. 279, 338-348.

316 Nakanishi N, Izawa M. 2016. Importance of frogs in the diet of the Iriomote cat based on 317 stomach content analysis. Mamm Res. 61:35-44.

318 Okinawa Prefecture 2018. A list of invasive species in Okinawa Prefecture. Okinawa Prefecture. 319 https://www.pref.okinawa.jp/site/kankyo/shizen/hogo/taisakugairaisyu-list.html [accessed 3205 December 2018] (in Japanese).

321 Pavey CR, Eldridge SR., Heywood M. 2008. Population dynamics and prey selection of native 
and introduced predators during a rodent outbreak in arid Australia. J Mammal. 89:674-

323 683.

324 Pucek Z, Jędrzejewski W, Jędrzejewska B, Pucek M. 1993. Rodent population dynamics in a 325 primeval deciduous forest (Białowieża National Park) in relation to weather, seed crop, and 326 predation. Acta Theriol. 38:199-232.

327 Pineda-Munoz S, Alroy J. 2014. Dietary characterization of terrestrial mammals. Proc Royal Soc $328 \quad$ B: Biol Sci. 281(1789):20141173.

329 Renken RB, Gram WK, Fantz DK, Richter SC, Miller TJ, Ricke KB, Russel B, Wang X. 2004. 330 Effects of forest management on amphibians and reptiles in Missouri Ozark forests. Cons 331 Biol. 18:174-188.

332 Ross J, Brodie J, Cheyne S, Hearn A, Izawa M, Loken B, Lynam A, McCarthy J, Mukherjee S, 333 Phan C, Rasphone A, Wilting A. 2015. Prionailurus bengalensis. The IUCN Red List of 334 Threatened Species: e.T18146A50661611. http://dx.doi.org/10.2305/IUCN.UK.2015335 4.RLTS.T18146A50661611.en. [Accessed 2 April 2018].

336 Sakaguchi N, Ono Y. 1994. Seasonal change in the food habits of the Iriomote cat Felis 337 iriomotensis. Ecol Res. 9:167-174.

338 Tatara M, Doi T. 1994. Comparative analyses on food habits of Japanese marten, Siberian 339 weasel and leopard cat in the Tsushima islands, Japan. Ecol Res. 9:99-107.

340 Van Valkenburgh, B. 2007. Déjà vu: the evolution of feeding morphologies in the Carnivora. 341 Integr. Compar Biol. 47:147-163.

342 Virgós E, Llorente M, Cortésá Y. 1999. Geographical variation in genet (Genetta genetta L.) 343 diet: a literature review. Mamm Rev. 29:117-126. 
344 Watanabe S. 2009. Factors affecting the distribution of the leopard cat Prionailurus bengalensis 345 on East Asian islands. Mamm Stud. 34:201-207.

346 Watanabe S. 2012. Ecological Flexibility of the Top Predator in an Island Ecosystem — Food 347 Habit of the Iriomote Cat, in: Mahamane, A. (Eds.) Diversity of Ecosystems. IntechOpen, 348 London, pp. 465-484.

349 Watanabe S, Nakanishi N, Izawa M. 2003. Habitat and prey resource overlap between the 350 Iriomote cat Prionailurus iriomotensis and introduced feral cat Felis catus based on assessment of scat content and distribution. Mamm Stud. 28:47-56.

352 Wolf C, Ripple WJ. 2016. Prey depletion as a threat to the world's large carnivores. Royal Soc. $353 \quad$ Open Sci. 3:160252.

354 Zhou YB, Newman C, Buesching CD, Zalewski A, Kaneko Y, Macdonald DW, Xie ZQ. 2011. 355 Diet of an opportunistically frugivorous carnivore, Martes flavigula, in subtropical forest. J $356 \quad$ Mammal. 92:611-619. 


\section{$358 \quad$ Figure legends}

359 Fig. 1. Geographical locations of leopard cat dietary studies used in the meta-analysis. Ir

360 (Iriomote Island, Japan), Si (Singapore), Ba (Bangladesh), Ph (Philippines), Bo (Borneo,

361 Malaysia), In (India), Ko (Korea), Ts (Tsushima Island, Japan). Leopard cat distribution range is

362 shaded on the map (based on Ross et al. 2015). The leopard cat illustration was provided

363 courtesy of Xingwen Loy.

364

365 Fig. 2. Comparing food composition of the leopard cat between the 'mainland' $(N=7)$ and

366 'Iriomote Island' $(N=4)$, shown as the relative frequency of occurrence (RFO). Boxplots show

367 median (horizontal bars) with 25 and $75 \%$ quartiles and vertical bars give maximum and

368 minimum values. ${ }^{*} P<0.05$ (significance detected only by Mann-Whitney $U$ test). ${ }^{* *} P<0.05$

369 (significance detected by Chi-squared test, G-test, and Mann-Whitney $U$ test; see Supplementary 370 Information).

372 Fig. 3. Geographical variations in leopard cat food composition depicted by principal component 373 analysis. Abbreviations: SMamm = Small mammals, OthMamm = Other mammals, Rept $=$

374 Reptiles, Amp = Amphibians, Inv = Invertebrates; $\mathbf{I r 1 - 4}=$ Iriomote Island, $\mathbf{S i}=$ Singapore, $\mathbf{B a}=$ 375 Bangladesh, $\mathbf{P h}=$ Philippines, $\mathbf{B o}=$ Borneo, $\mathbf{I n}=$ India, $\mathbf{K o}=$ Korea, $\mathbf{T s}=$ Tsushima Island $($ see 376 references in Table 1). 
1 Table 1. Summary of study areas from the reviewed papers of the leopard cat across Asia. 'Iriomote' = Iriomote Island, Japan;

2 'Mainland' = the rest of other study areas (see Fig. 1).

\begin{tabular}{|c|c|c|c|c|c|c|c|c|c|}
\hline & \multirow{2}{*}{$\begin{array}{c}\text { 'Iriomote' } \\
\text { Ir1-Ir4 }\end{array}$} & \multicolumn{7}{|c|}{ 'Mainland' } & \multirow{2}{*}{ Total } \\
\hline & & Si & $\mathbf{B a}$ & $\mathbf{P h}$ & Bo & In & Ko & Ts & \\
\hline Compiled publication $(N)$ & 4 & 1 & 1 & 1 & 1 & 1 & 1 & 1 & 11 \\
\hline Analysed sample $(n)^{\mathrm{a}}$ & 1311 & 65 & 21 & 51 & 72 & 37 & 280 & 350 & 2187 \\
\hline \multicolumn{10}{|l|}{ Trophic diversity } \\
\hline $\begin{array}{l}\text { Shannon's diversity } \\
\text { index }\left(H^{\prime}\right)^{\mathrm{b}}\end{array}$ & $\begin{array}{r}1.66 \pm \\
0.06\end{array}$ & & 1.18 & 0.93 & 0.94 & 0.7 & 0.69 & 1.32 & $1.07 \pm 0.11$ \\
\hline $\begin{array}{l}\text { Levins' niche breadth } \\
\text { index }(B)^{\mathrm{b}}\end{array}$ & $\begin{array}{r}4.74 \pm \\
0.34\end{array}$ & 2.63 & 2.94 & 1.72 & 1.81 & 1.64 & 1.49 & 2.93 & $2.49 \pm 0.36$ \\
\hline \multicolumn{10}{|l|}{ Geo-climatic variable } \\
\hline Latitude $\left({ }^{\circ}\right)^{\mathrm{c}}$ & 24.2 & 1.2 & 21.9 & 10.4 & 5.1 & 27.3 & 37.9 & 34.2 & $20.3 \pm 4.4$ \\
\hline Elevation $(\mathrm{m})^{\mathrm{d}}$ & 300 & 10 & 10 & 506 & 72 & 3562 & 1068 & 200 & $716 \pm 398$ \\
\hline $\begin{array}{l}\text { Annual mean } \\
\text { temperature }\left({ }^{\circ} \mathrm{C}\right)^{\mathrm{e}}\end{array}$ & 23.1 & 35.8 & 22.9 & 28.9 & 32.8 & 5.8 & 5.8 & 14.8 & $21.2 \pm 3.8$ \\
\hline $\begin{array}{l}\text { Annual mean } \\
\text { precipitation }(\mathrm{mm})^{\mathrm{e}}\end{array}$ & 2073.4 & 1269.9 & 614.3 & 1064.2 & 1194.1 & 437.8 & 1088.7 & 2060.9 & $1225.4 \pm 196.0$ \\
\hline $\begin{array}{l}\text { Inhabitation by native } \\
\text { rodents }^{\mathrm{f}}\end{array}$ & Absent & Present & Present & Present & Present & Present & Present & Present & \\
\hline
\end{tabular}

3 Ir1 (Sakaguchi \& Ono 1994; analysed sample $n=177$ ), Ir2 (Watanabe et al. 2003; $n=156$ ), Ir3 (Watanabe 2012; $n=947$ ), Ir4

4 (Nakanishi \& Izawa 2016; $n=31$ ), Si (Singapore: Chua et al. 2016), Ba (Bangladesh: Khan 2004), Ph (Philippines: Lorica \& Heaney,

5 2013), Bo (Borneo, Malaysia: Rajaratnam et al. 2007), In (India: Bashir et al. 2014), Ko (Korea: Lee et al. 2014), Ts (Tsushima 
6 Island, Japan: Tatara \& Doi 1994).

7 a Summed across studies for Iriomote Island and total (the sample size for each study in Iriomote Island is noted in the footnote

8 above).

9 b Values are the mean and standard error for Iriomote Island and total.

$10{ }^{\mathrm{c}}$ Extracted from each publication and averaged across provided range in each study.

$11 \mathrm{~d}$ Extracted from each publication. When the information was not provided, we used the elevation function in $R$ package $r g b i f$ to 12 extract data from Google Maps.

13 e Obtained by BioSIM 11 software based on latitude, longitude, and elevation information (between 1982 and 2010 ).

$14{ }^{\mathrm{f}}$ Absent: native rodents were absent in the study area. Present: native rodents were present in the study area. 
Fig. 1

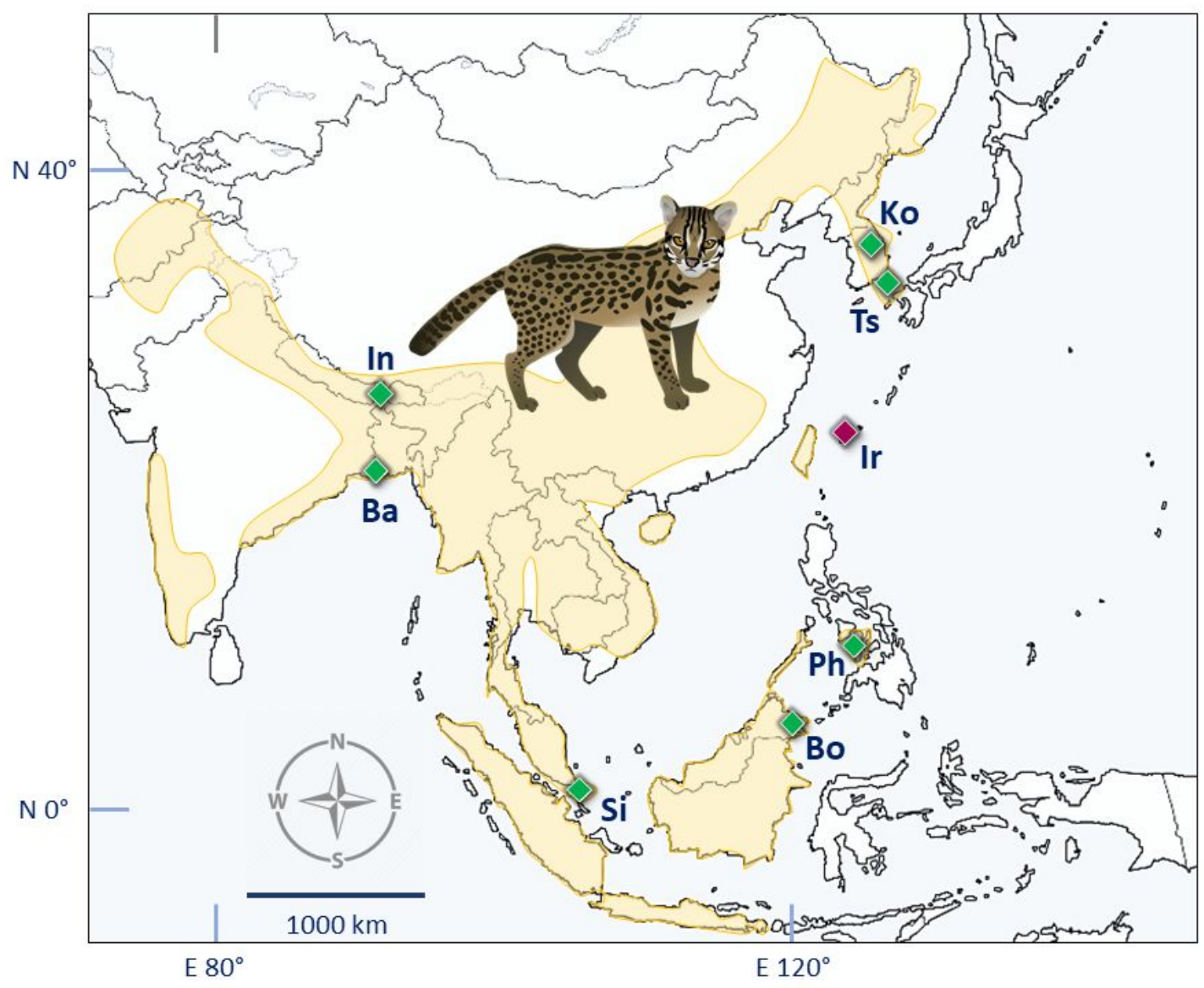


Fig. 2

5

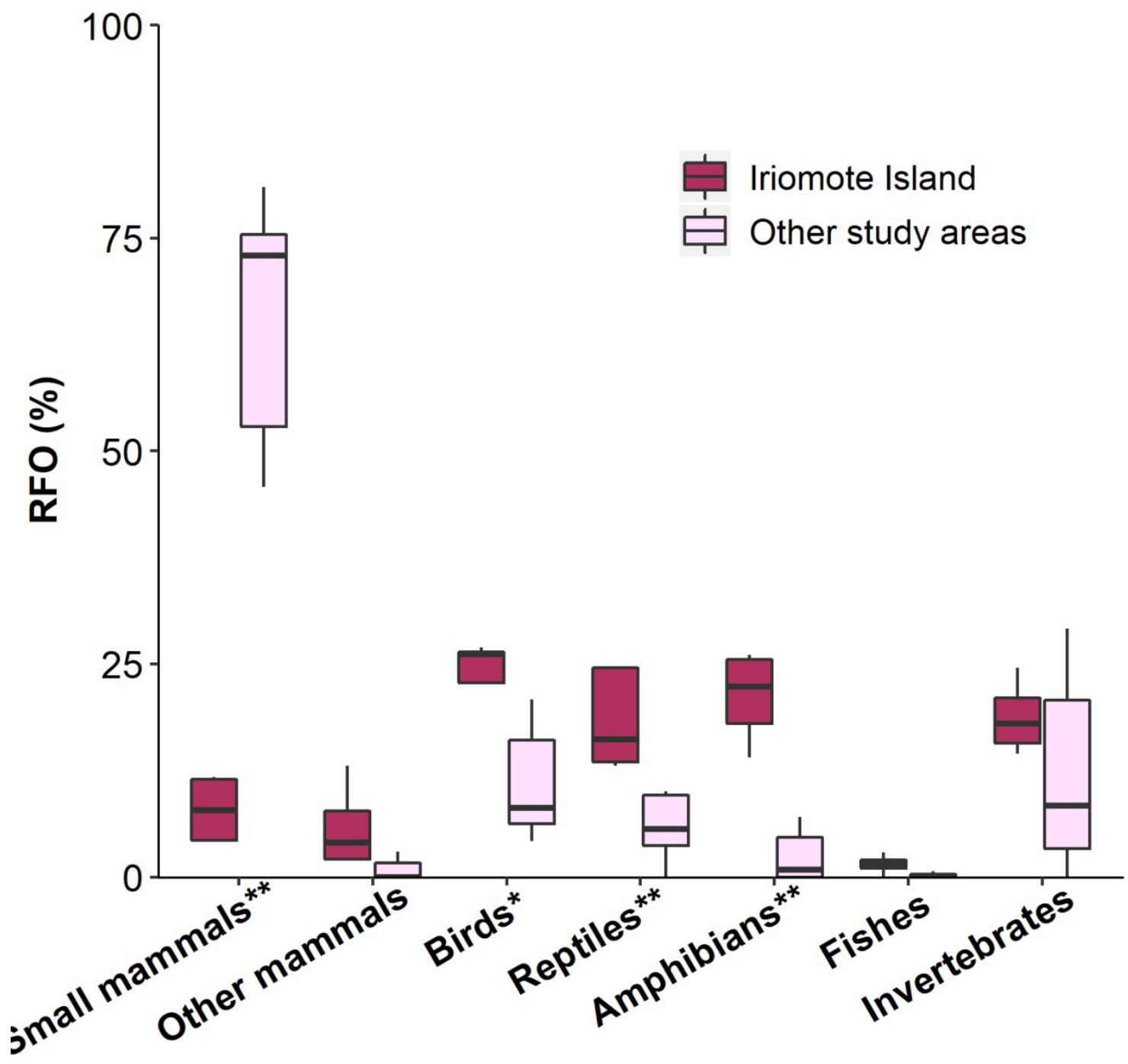


9 Fig. 3

1

2

3

4

5

6

7

8

10

11

12

13

14

15

16

17

18

19

20

21

22

23

24

25

26

27

28

29

30

31

32

33

34

35

36

37

38

39

40

41

42

43

44

45

46

47

48

49

50

51

52

53

54

55

56

57

58

59

60

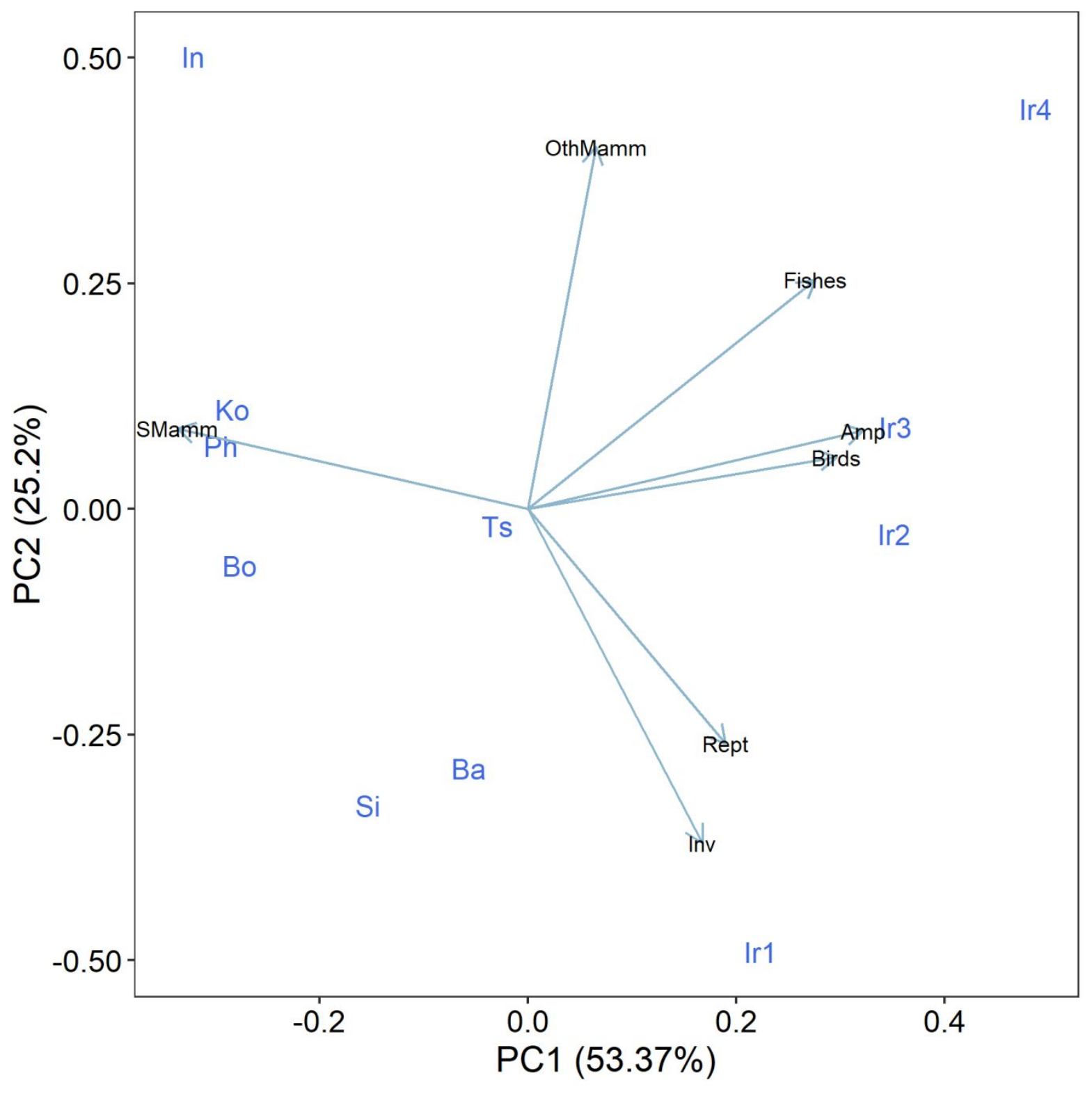


1 Supplementary Information for

2 Adaptations to prey base in the hypercarnivorous leopard cat Prionailurus bengalensis

3

4 Masumi Hisano and Chris Newman

5 Contact information: mhisano@lakeheadu.ca (M. Hisano)

6

7 This file includes:

8 Supplementary Methods

$9 \quad$ Tables S1 and S2

10 References for Supplementary Information

11 


\section{Supplementary Methods \\ 13 Assessing possible methodological problems}

14 1. The dataset compiled included inconsistent sampling methodologies [one study (Nakanishi 15 and Izawa 2016) examined stomach contents, while all the others were based upon faecal 16 analysis], sample sizes (number of analysed faeces or stomachs, $n$ ), and sampling durations

17 (months). To check if these artefacts caused bias in interpreting leopard cat diet bias 18 (Putman, 1984: cf. Lozano et al., 2006; Zhou et al., 2011), we performed a permutational 19 multivariate analysis of variance (PERMANOVA) using the R package vegan (Oksanen et 20 al., 2015). We defined sampling as sample size per month ( $n /$ month) for each study to 21 avoid multicollinearity (Dormann et al., 2013) between the sample size and duration $(r=$ 22 0.77). Across studies, there was no significant influence arising from sampling effort 23 variation (PERMANOVA: $\left.F=0.88, R^{2}=0.08, P=0.450\right)$ and methodology $\left(F=1.64, R^{2}=\right.$ $240.16, P=0.244$ ) on RFO per food category. Alternatively, we excluded the study employed 25 stomach contents analysis (Nakanishi \& Izawa 2016) and repeated the PERMANOVA and 26 subsequent post-hoc tests to assess differences in diet composition between Iriomote and the 27 mainland (see the main analysis described in Materials and methods in the main text). This 28 approach produced similar results: PERMANOVA $\left(F=10.72, R^{2}=0.57, P=0.055\right)$, 29 Chi-squared tests $(P<0.001$ for small mammals, $P<0.001$ for reptiles, $P=0.002$ for 30 amphibians). Consequently, all the 11 studies were used for subsequent analyses (Table S2; $31 \quad$ Fig. 1).

32 2. In one study from India, the leopard cat consumed a considerable amount of carrion $(16.7 \%$ 33 RFO vs $0-5 \%$ elsewhere). To investigate whether our results were influenced or biased by 34 dietary intake resulting from consumption of carrion against hunted prey, we also repeated 
35 the main PERMANOVA analysis (see Materials and methods in the main text) to compare

36 leopard cat food composition between Iriomote and the mainland by removing the food

37 items being considered as carrion (i.e., ungulates). This approach yielded consistently

38 Similar results (PERMANOVA: $F=26.51, R^{2}=0.75, P=0.016$ ), and thereby we discuss the

39 results based on the main results including both hunted prey and carrion.

40 3. To compare RFO of each food category specifically between mainland sites vs Iriomote, in 41 addition to the Chi-squared test, we also employed likelihood ratio test [ $G$-test, a more 42 conservative approach, which can reduce the potential for type I error (Malo et al., 2004;

43 Lozano et al. 2006)] and a rank-based method (Mann-Whitney $U$ test) to confirm the 44 robustness of the analysis. Alternative approaches also showed that this lack of small 45 mammals on Iriomote $(G$-test: $P<0.001$, Mann-Whitney $U$ test: $P=0.016)$ was 46 compensated by consuming more reptiles $(G$-test: $P=0.001$, Mann-Whitney $U$ test: $P=$ 47 0.028), and amphibians $(G$-test: $P<0.001$, Mann-Whitney $U$ test: $P=0.021)$; with mixed 48 support for a greater consumption of birds (Mann-Witney $U$ test: $P=0.024$; versus $G$ test: $P$ $49=0.070)$. 
50 Table S1. A list of 24 dietary studies reviewed on the leopard cat.

\begin{tabular}{ll}
\hline Source & Geographical location \\
\hline Studies that met the screening criteria and were & included in the analysis \\
Bashir et al. (2014) & Sikkim, Northern India \\
Chua et al. (2016) & Pulau Tekong, Singapore \\
Khan (2004) & Ganges Delta, Eastern India/Southern Bangladesh \\
Lorica and Heaney (2013) & Hacienda Dos Marias, Phillippines \\
Lee et al. (2014) & Gangwon, Gyeongsangbuk, South Korea \\
Nakanishi and Izawa (2016) & Iriomote Island, Southern Japan \\
Rajaratnam et al. (2007) & Sabah, Northern Borneo, Malaysia \\
Sakaguchi and Ono (1994) & Iriomote Island, Southern Japan \\
Watanabe (2012) & Iriomote Island, Southern Japan \\
Tatara and Doi (1994) & Tsushima Island, Western Japan \\
Watanabe et al. (2003) & Iriomote Island, Southern Japan
\end{tabular}

\section{Studies that did not meet the screening criteria}

Bao et al. (2005)

Inoue (1972)

Fernandez and De Guia (2011)

Grassman (2000)

Grassman et al. (2005)

Lee et al. (2013)

Rabinowitz (1990)

Díaz-Sacco and Izawa (2013)

Sakaguchi (1994)

Japan Wildlife Research Center (1998)

Watanabe and Izawa (2005)

Izawa et al. (2000)

Watanabe (2015)
Beijing, Northern China

Tsushima Island, Western Japan

La Carlota, Central Philippines

Kaeng Krachan, Central Thailand

Phu Khieo, Northern Thailand

Samcheok, Goheung, Gwangju, South Korea

Huai Kha Khaeng, Central Thailand

Iriomote Island, Southern Japan

Tsushima Island, Western Japan

Tsushima Island, Western Japan

Iriomote Island, Southern Japan

NA

Iriomote Island, Southern Japan

51 See Materials and methods in the main text for the inclusion criteria. 
52 Table S2. Results from the principal components analysis (PCA) of using the seven food 53 categories.

\begin{tabular}{lrrrr}
\hline \multicolumn{1}{r}{ Variables } & Factor 1 & Factor 2 & Factor 3 & \multicolumn{1}{c}{ Factor 4 } \\
\hline Small mammals & -0.50 & 0.13 & 0.14 & 0.15 \\
Other mammals & 0.10 & 0.60 & -0.39 & -0.67 \\
Birds & 0.44 & 0.09 & 0.47 & -0.05 \\
Reptiles & 0.28 & -0.39 & -0.69 & 0.15 \\
Amphibians & 0.48 & 0.13 & -0.12 & 0.35 \\
Fishes & 0.41 & 0.38 & 0.20 & 0.23 \\
Invertebrates & 0.25 & -0.55 & 0.28 & -0.57 \\
\hline
\end{tabular}

54

55 


\section{References for Supplementary Information}

57 Bao W, Xiao-jing L, Yang S (2005) Comparative analysis of food habits in carnivores from three

Bashir T, Bhattacharya T, Poudyal K, Sathyakumar S, Qureshi Q (2014) Integrating aspects of ecology and predictive modelling: implications for the conservation of the leopard cat (Prionailurus bengalensis) in the Eastern Himalaya. Acta Theriol 59:35-47

Chua MA, Sivasothi N, Meier R (2016) Population density, spatiotemporal use and diet of the leopard cat (Prionailurus bengalensis) in a human-modified succession forest landscape of Singapore. Mamm Res 61:99-108

Díaz-Sacco JJ, Izawa M (2013) Road use by the Iriomote cat (Prionailurus bengalensis iriomotensis) on Iriomote-jima Island in relation to its herpetile prey. Mamm stud 38:73-81

Dormann CF, Elith J, Bacher S, Buchmann C, Carl G, Carre G, Marquez JRG, Gruber B, Lafourcade B, Leitao PJ, Munkemuller T, McClean C, Osborne PE, Reineking B, Schroder B, Skidmore AK, Zurell R, and Lautenbach S (2013) Collinearity: a review of methods to deal with it and a simulation study evaluating their performance. Ecography 36:27-46

Fernandez DAP, De Guia APO (2011) Feeding habits of Visayan leopard cats (Prionailurus bengalensis rabori) in sugarcane fields of Negros Occidental, Philippines. Asia International Journal of Life Sciences 20:143-154

Grassman L (2000) Movements and diet of the leopard cat Prionalilurus bengalensis in a seasonal evergreen forest in south-central Thailand. Acta Theriol 45:421-426

Grassman LI, Tewes ME, Silvy NJ, Kreetiyutanont K (2005) Spatial organization and diet of the leopard cat (Prionailurus bengalensis) in north-central Thailand. J Zool 266:45-54

Hisano M, Newman C, Deguchi S, Kaneko Y (2019) Thermal forest zone explains regional 


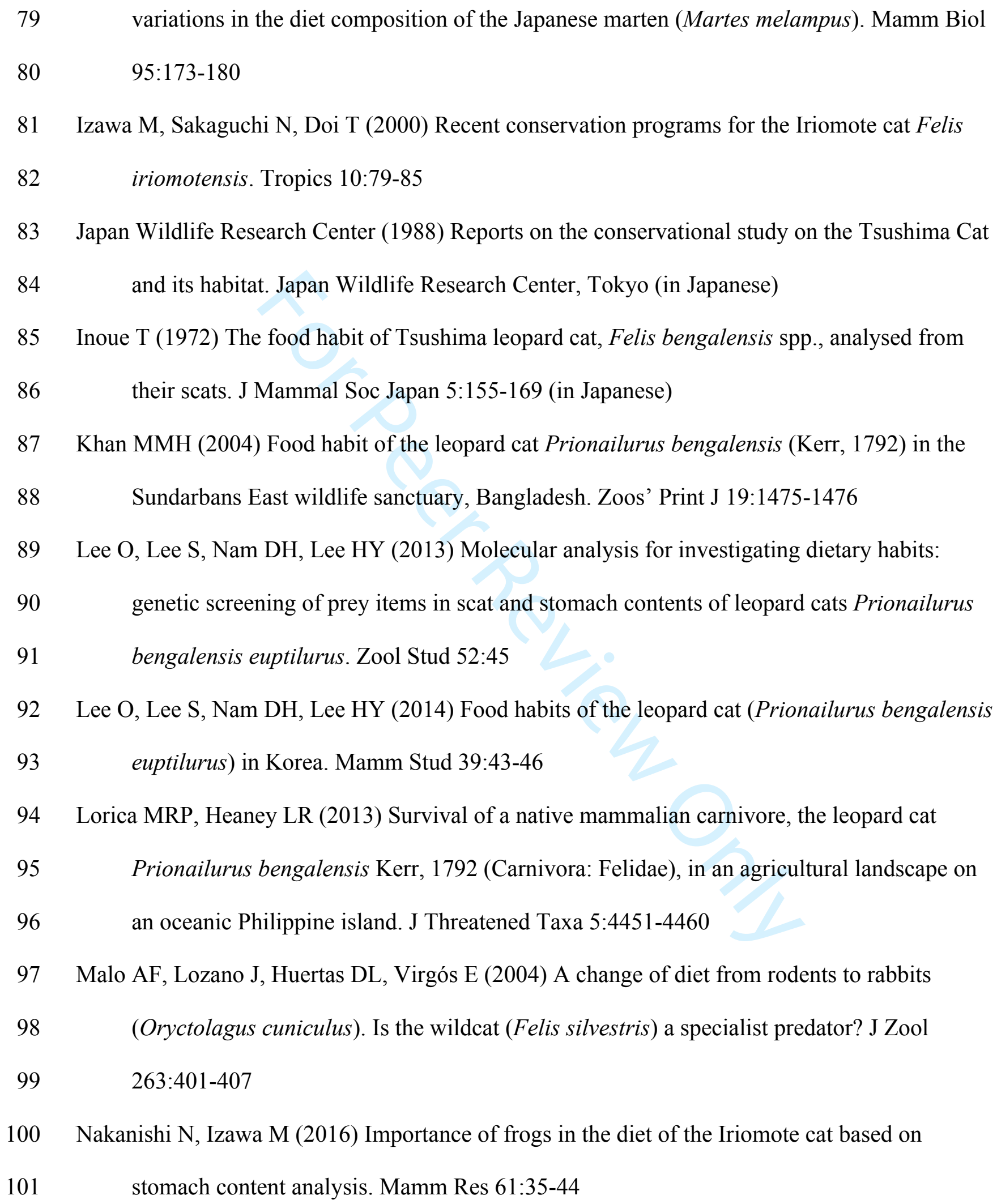

81 Izawa M, Sakaguchi N, Doi T (2000) Recent conservation programs for the Iriomote cat Felis 82 iriomotensis. Tropics 10:79-85

83 Japan Wildlife Research Center (1988) Reports on the conservational study on the Tsushima Cat $84 \quad$ and its habitat. Japan Wildlife Research Center, Tokyo (in Japanese)

85 Inoue T (1972) The food habit of Tsushima leopard cat, Felis bengalensis spp., analysed from 86 their scats. J Mammal Soc Japan 5:155-169 (in Japanese)

87 Khan MMH (2004) Food habit of the leopard cat Prionailurus bengalensis (Kerr, 1792) in the 88 Sundarbans East wildlife sanctuary, Bangladesh. Zoos’ Print J 19:1475-1476

89 Lee O, Lee S, Nam DH, Lee HY (2013) Molecular analysis for investigating dietary habits:

90 genetic screening of prey items in scat and stomach contents of leopard cats Prionailurus

91 bengalensis euptilurus. Zool Stud 52:45

92 Lee O, Lee S, Nam DH, Lee HY (2014) Food habits of the leopard cat (Prionailurus bengalensis 93 euptilurus) in Korea. Mamm Stud 39:43-46

94 Lorica MRP, Heaney LR (2013) Survival of a native mammalian carnivore, the leopard cat 95 Prionailurus bengalensis Kerr, 1792 (Carnivora: Felidae), in an agricultural landscape on 96 an oceanic Philippine island. J Threatened Taxa 5:4451-4460

97 Malo AF, Lozano J, Huertas DL, Virgós E (2004) A change of diet from rodents to rabbits 98 (Oryctolagus cuniculus). Is the wildcat (Felis silvestris) a specialist predator? J Zool $99 \quad 263: 401-407$

100 Nakanishi N, Izawa M (2016) Importance of frogs in the diet of the Iriomote cat based on 101 stomach content analysis. Mamm Res 61:35-44 
102 Oksanen J, Blanchet FG, Kindt R, Legendre P, Minchin PR, O’Hara RB, Simpson GL, Solymos

103 P, Stevens MHH, Wagner H (2015) vegan: Community Ecology Package. R package

$104 \quad$ version $2.5-1$

105 Putman RJ 1984 Facts from faeces. Mamm Rev 14:79-97

106 Rabinowitz, A (1990) Notes on the behavior and movements of leopard cats, Felis bengalensis, 107 in a dry tropical forest mosaic in Thailand. Biotropica 22:397-403.

108 Rajaratnam R, Sunquist M, Rajaratnam L, Ambu L (2007) Diet and habitat selection of the 109 leopard cat (Prionailurus bengalensis borneoensis) in an agricultural landscape in Sabah, $110 \quad$ Malaysian Borneo. J Trop Ecol 23:209-217

111 Sakaguchi N (1994) Ecological aspects and social system of the Iriomote cat Felis iriomotensis 112 (Carnivore; Felidae): Ph. D. thesis, Kyushu University, Fukuoka

113 Sakaguchi N, Ono Y (1994) Seasonal change in the food habits of the Iriomote cat Felis $114 \quad$ iriomotensis. Ecol Res 9:167-174

115 Tatara M, Doi T (1994) Comparative analyses on food habits of Japanese marten, Siberian 116 weasel and leopard cat in the Tsushima islands, Japan. Ecol Res 9:99-107

117 Watanabe S (2012) Ecological Flexibility of the Top Predator in an Island Ecosystem — Food 118 Habit of the Iriomote Cat. In: Mahamane Ali (ed) Diversity of Ecosystems. IntechOpen, 119 London, pp 465-484

120 Watanabe, S (2015) Ecological Flexibility of the Top Predator in an Island Ecosystem — The 121 Iriomote Cat Changes Feeding Patterns in Relation to Prey Availability. In: Yueh-Hsin Lo, 122 Juan A. Blanco, Shovonlal Roy (ed) Biodiversity in Ecosystems-Linking Structure and 123 Function. IntechOpen, London, pp 353-381

124 Watanabe S, Izawa M (2005) Species composition and size structure of frogs preyed by the 8 
125 Iriomote cat Prionailurus bengalensis iriomotensis. Mamm Stud 30:151-155

126 Watanabe S, Nakanishi N, Izawa M (2003) Habitat and prey resource overlap between the 127 Iriomote cat Prionailurus iriomotensis and introduced feral cat Felis catus based on 128 assessment of scat content and distribution. Mamm Stud 28:47-56 129 